UDC 349.6

LBC 67.404.2+67.407

\title{
INDEMNIFICATION FOR HARM CAUSED TO HEALTH OF A PERSON BY AN ECOLOGICAL OFFENCE
}

\author{
Alexey P. Anisimov \\ Volgograd Institute of Management - RANEPA Branch, Volgograd, Russian Federation \\ Yuliya E. Kayushnikova \\ Volgograd Institute of Management - RANEPA Branch, Volgograd, Russian Federation
}

Introduction: the current state of the environment in Russia causes a reasonable alarm. The negative factors of the environment (pollution of atmospheric air, water, food, physical factors - noise, electromagnetic fields, etc.) exert the increasing impact on the health condition of the population. However, the specifics of indemnification for the harm caused to the life and health of a person by an ecological offense are yet not adequately investigated. In the article the authors set a research objective - to investigate the mechanism of compensation for the ecological harm caused to the health of the citizens. Methods: the methodological framework of the research is a set of methods of scientific knowledge among which the main are the methods of system analysis, historicism, and the comparative law method. Results: in the article the modern problems of indemnification for the harm caused to the life and health of the citizens by the influence of the earlier polluted environment are investigated and it is proved that such harm can be compensated in three main ways: by ecological insurance, in a judicial proceeding, and also in an administrative (public) order. Conclusions: there are a number of shortcomings of the operating procedures of compensation for ecological harm to the health of the citizens covered by the civil and ecological legislation, connected with calculating the extent of the harm caused (including compensations for moral harm); lack of the accurate mechanism of bringing offenders to the compensation for ecological harm; the process of proving the guilt of persons who caused the ecological harm is insufficiently regulated. One of the ways of solving this complex of problems could become the adoption of the special Federal law "On Indemnification for Harm Caused to Life and Health of Citizens by Ecological Offences" which could detail the order and ways of compensation for ecological harm caused to life and health of the citizens. The bill of such a law was drafted twenty years ago; however, it has not been adopted as yet which demands the correction.

Key words: ecological harm, health of a person, negative condition of the environment, moral harm, indemnification, air, water, soils.

УДК 349.6

ББК 67.404.2+67.407

\section{ВОЗМЕЩЕНИЕ ВРЕДА, ПРИЧИНЕННОГО ЗДОРОВЬЮ ЧЕЛОВЕКА ЭКОЛОГИЧЕСКИМ ПРАВОНАРУШЕНИЕМ}

\author{
Алексей Павлович Анисимов \\ Волгоградский институт управления - филиал РАНХиГС, г. Волгоград, Российская Федерация \\ Юлия Евгеньевна Каюшникова \\ Волгоградский институт управления - филиал РАНХиГС, г. Волгоград, Российская Федерация
}

Введение: современное состояние окружающей среды в России вызывает обоснованную тревогу. Негативные факторы окружающей среды (загрязнение атмосферного воздуха, воды, продуктов питания, физические факторы - шум, электромагнитные поля и т. д.) оказывают все большее влияние на состояние здоровья населения. Однако специфика возмещения вреда жизни и здоровью человека, причиненного эколо- 
гическим правонарушением, до сих пор исследована явно недостаточно. В статье поставлена цель - исследование механизма возмещения экологического вреда здоровью граждан. Методы: методологическую основу данного исследования составляет совокупность методов научного познания, среди которых основное место занимают методы системного анализа, историзма и сравнительно-правовой метод. Результаты: в статье исследованы современные проблемы возмещения вреда жизни и здоровью граждан, причиненного воздействием ранее загрязненной окружающей среды, и обосновано, что такой вред может быть возмещен тремя основными способами: путем экологического страхования, в судебном порядке, а также в административном (публичном) порядке. Выводы: существует ряд недостатков действующих процедур возмещения экологического вреда здоровью граждан, предусмотренных в гражданском и экологическом законодательстве, связанных с расчетом размера причиненного вреда (в том числе компенсации морального вреда); отсутствием четкого механизма привлечения правонарушителей к возмещению экологического вреда; недостаточно регламентирован процесс доказывания вины причинителей экологического вреда. Одним из вариантов решения этого комплекса проблем могло бы стать принятие специального Федерального закона «О возмещении вреда, причиненного жизни и здоровью граждан экологическими правонарушениями», который мог бы детализировать порядок и способы возмещения экологического вреда жизни и здоровью граждан. Проект такого закона был разработан двадцать лет назад, однако он до сих пор не был принят, что требует исправления.

Ключевые слова: экологический вред, здоровье человека, негативное состояние окружающей среды, моральный вред, возмещение вреда, воздух, вода, почвы.

\section{Введение}

Современное состояние окружающей среды в России вызывает обоснованную тревогу. Негативные факторы окружающей среды (загрязнение атмосферного воздуха, воды, продуктов питания, физические факторы шум, электромагнитные поля и т. д.) оказывают все большее влияние на состояние здоровья населения. По данным Всемирной организации здравоохранения (структурного подразделения $\mathrm{OOH})$, неблагоприятные природные факторы являются причиной дополнительных 13 млн смертей населения в мире каждый год. Около 19 \% всех онкологических заболеваний, 1/3 всех заболеваний детей в возрасте до пяти лет, усугубление сердечно-сосудистых и легочных заболеваний - это еще не исчерпывающий перечень последствий загрязнения окружающей среды. При этом необходимо обратить внимание на то, что большая часть негативных последствий для жизни и здоровья человека от ухудшения качества окружающей среды до сих пор не изучена. Главным фактором, влекущим медико-демографические потери в России, является физическое, химическое и биологическое загрязнение окружающей среды. Примерная численность населения, наиболее подверженного негативному воздействию окружающей среды от факторов химического загрязнения продуктов питания, питьевой воды, воздуха и почвы, в 2015 г. составила 89,08 млн человек $(90,34$ млн человек в 2014 г.). Биологическая нагрузка, определяемая микробиологическим загрязнением продуктов питания, воды и почвы, стала основной для населения общей численностью около 61 млн человек (60 млн человек в 2014 г.) [4, с. 242]. Таким образом, наличие в атмосферном воздухе, воде и почвах вредных химических или биологических веществ в количествах, превышающих предельно допустимые концентрации, создает угрозу жизни и здоровью человека, что требует исследования механизма гражданско-правовой защиты конституционного права граждан России на благоприятную окружающую среду.

\section{Общие положения о возмещении экологического вреда}

В теории экологического и гражданского права проблемы возмещения экологического вреда обычно рассматривают как межотраслевой правовой институт, включающий нормы различной отраслевой принадлежности, в том числе нормы гражданского, финансового и экологического права [8]. При этом само понятие «экологический вред» включает в себя, во-первых, вред, причиненный окружающей среде (лесам, водам, почвам и т. д.), который можно назвать «первичный вред», и, во-вторых, вред, причиненный жизни, здоровью или имуществу граждан (иму- 
ществу юридических лиц) в результате вредного воздействия загрязненной окружающей среды (вторичный вред). Последнюю разновидность вреда в теории экологического права еще называют «экогенный вред» [2, с. 294].

Несомненно, защита экологических конституционных прав может осуществляться не только средствами гражданского права, но и посредством самого широкого арсенала правовых средств иной отраслевой принадлежности, включая обращения граждан в органы государственной власти и местного самоуправления с жалобами и заявлениями о нарушении их экологических прав хозяйствующими субъектами или должностными лицами органов публичной власти. Однако если рассматривать данную проблему в более узком контексте, то можно прийти к выводу о том, что вред жизни и здоровью человека, причиненный воздействием ранее загрязненной окружающей среды, может быть возмещен тремя основными способами: путем экологического страхования, в судебном порядке, а также в административно-правовом (публичном) порядке.

Экологическое страхование гражданскоправовой ответственности юридических лиц за причинение вреда жизни, здоровью и имуществу граждан (имуществу юридических лиц) в результате негативного воздействия на окружающую среду последствий аварий и техногенных катастроф на подконтрольных им объектах, а также в результате воздействия загрязненной окружающей среды нанаселение и территории предполагает уплату страховых взносов, из которых возмещается вред, причиненный экологическим правонарушением. Экологическое страхование согласно гражданскому и экологическому законодательству может быть добровольным и обязательным. Добровольное экологическое страхование пока не получило в России особого развития, а наиболее известным примером обязательного экологического страхования являются требования п. 4 ст. 8 Федерального закона от 21 июля 1997 г. № 116-Ф3 «О промышленной безопасности опасных производственных объектов» о том, что для ввода в эксплуатацию опасного производственного объекта, среди прочего, необходимо наличие у эксплуатирующей данный объект организации договора обязательного страхования гражданской ответственности, заключенного в соответствии с федеральным законодательством об обязательном страховании гражданской ответственности владельца опасного объекта за причинение вреда в результате аварии на опасном объекте. Однако сфера обязательного экологического страхования охватывает лишь часть промышленных объектов, представляющих особую опасность для окружающей среды и человека.

Судебный порядок предполагает обращение гражданина в суд с требованием о возмещении вреда жизни, здоровью или имуществу, причиненного в результате экологического правонарушения. Согласно ст. 1 Федерального закона от 10 января 2002 г. № 7-Ф3 «Об охране окружающей среды» вред окружающей среде - это ее негативное изменение в результате загрязнения, которое повлекло за собой деградацию естественных экологических систем и истощение природных ресурсов. Из других норм данного закона следует вывод о том, что вред окружающей среде включает количественные и качественные потери, проявляющиеся в загрязнении окружающей среды (в том числе в физико-химическом изменении состава атмосферного воздуха, воды, почвы, создающем угрозу для здоровья населения, растительного и животного мира), в порче, повреждении, уничтожении природных объектов и экологических систем.

Согласно ст. 1085 ГК РФ при повреждении здоровья гражданина возмещению подлежит утраченный потерпевшим заработок (доход), который он имел либо определенно мог иметь, а также дополнительно понесенные расходы, вызванные повреждением здоровья, в том числе расходы на лечение, дополнительное питание, приобретение лекарств, протезирование, посторонний уход, санаторно-курортное лечение, приобретение специальных транспортных средств, подготовку к другой профессии, если установлено, что потерпевший нуждается в этих видах помощи и ухода и не имеет права на их бесплатное получение. Судебная практика по данному вопросу довольно скудна по объему, что обусловлено спецификой данной формы возмещения экологического вреда. 
Если гражданин, пострадавший от неблагоприятного воздействия окружающей среды, претендует на полное возмещение вреда здоровью или имуществу, он должен в предусмотренном законом порядке доказать наличие вреда и его причинной связи с противоправным поведением причинителя вреда. Другими словами, доказыванию подлежит несколько юридических фактов:

1. Факт совершения ответчиком деяния, нарушившего экологическое законодательство. Например, нарушение экологического законодательства часто влечет за собой наложение административных санкций. Постановление о наложении таких мер административного воздействия может быть одним из доказательств факта совершения противоправного экологического деяния.

2. Факт причинения вреда окружающей среде в результате экологического правонарушения. Кроме материалов административного производства данный факт может быть доказан актом органа государственного экологического надзора о факте загрязнения окружающей среды в определенное время и место.

3. Факт причинения вреда здоровью и имуществу гражданина. Его должен документально подтвердить сам потерпевший, предоставив справку о состоянии здоровья, больничный лист, чеки о приобретении лекарств, дополнительном питании и т. п. Наряду с возмещением вреда здоровью и имуществу, причиненного экологическим правонарушением, гражданин имеет право на компенсацию морального вреда, размер которого он должен обосновать.

4. Причинно-следственная связь между негативным воздействием окружающей среды и самим вредом. Данный предмет доказывания является наиболее сложным. Необходимо доказать факт нахождения лица в месте, где был причинен вред природе. Здесь возможно предоставление справки с места работы, места жительства и т. д., подтверждающей, что потерпевший в данное время находился в данном месте, следовательно, подвергался вредному воздействию окружающей среды. Суду будет необходимо выяснить, не вызваны ли такие последствия иными факторами, в том числе естественно-природными, и не наступили ли они вне зависи- мости от совершенного правонарушения, а также не совершены ли противоправные деяния в состоянии крайней необходимости.

\section{Возмещение экологического вреда в судебной практике}

Так, Ф. обратилась в суд с иском к ООО «Участок “Коксовый”» о признании незаконными действий по сооружению отвалов вскрышной породы, приостановлении деятельности, устранении вреда здоровью, компенсации морального вреда. Исковые требования были мотивированы тем, что ООО с 2002 г. ведет работу по добыче угля открытым способом и вывозит породу на отвалы недалеко от дома Ф., называя эту деятельность «рекультивацией нарушенных земель». Разгрузка породы на отвалах приводит к недопустимому повышению концентрации пыли в воздухе, что вредит здоровью людей. При этом ответчик умышленно утаивает экологическую информацию, находящуюся в проектной документации, в соответствии с которой проводятся работы, отказывает в ознакомлении с проектами производства работ. На основании этого Ф. просила суд признать незаконными действия ООО по сооружению отвалов вскрышной породы вблизи ее жилища и приостановить деятельность предприятия до приведения им своей хозяйственной деятельности в соответствие с требованиями санитарного законодательства, обязать ООО устранить причиняемый ее здоровью вред путем предоставления жилья в другом районе города Киселевска, а также взыскать с ООО в ее пользу компенсацию морального вреда.

Исследовав материалы дела, суд пришел к выводу о том, что представленные сведения о результатах лабораторных испытаний по измерению концентрации загрязняющих веществ в пробах атмосферного воздуха не свидетельствуют о прямой взаимосвязи с осуществлением хозяйственной деятельности ООО, поскольку не представлены инструментальные замеры общего фона по городу в данном районе (общей экологической обстановки), отсутствуют доказательства того, что в других районах города обстановка более благоприятная. При оценке полученного результата также следует учитывать наличие других 
источников выбросов, а именно городская автомобильная дорога, которая расположена вблизи дома истицы, наличие в непосредственной близости от нее иных источников загрязнения атмосферного воздуха (шахта «Киселевская»).

Таким образом, в судебном заседании не представлено доказательств того, что в результате производственной деятельности ответчика истице причинен какой-либо вред, в том числе физические и нравственные страдания (моральный вред), в связи с чем Ф. было отказано в удовлетворении иска [8].

Несмотря на то что подобного рода отказы в иске являются распространенным явлением, следует отметить и другую тенденцию, связанную с увеличением числа обращений граждан России в Европейский суд по правам человека. И хотя в Европейской конвенции по правам человека нет специальной статьи, посвященной защите экологических прав, данное обстоятельство не препятствует защите последних посредством апелляции к другим статьям Конвенции. В числе наиболее интересных дел по защите экологических прав человека в практике Европейского суда по правам человека следует выделить:

а) дело «Фадеева против Российской Федерации» (жалоба № 55723/00). Заявитель утверждала, что проживание в санитарно-защитной зоне металлургического завода причинило существенный вред ее здоровью. Соответственно в отношении ее было совершено нарушение ст. 8 Конвенции в связи с неисполнением РФ своих обязанностей по защите частной жизни и жилища гражданки от значительной экологической угрозы в результате производственной деятельности ОАО «Северсталь». В итоге в Постановлении ЕСПЧ от 9 июня 2005 г. было указано, что имело место нарушение ст. 8 Конвенции, и на Россию была возложена обязанность по выплате Ф. в порядке компенсации морального вреда в сумме 6000 евро, а также по возмещению всех ее судебных расходов;

б) дело «Ледяева и другие против Российской Федерации». Европейским судом по правам человека было установлено, что отсутствие защиты от загрязнения окружающей среды является нарушением права на уважение частной жизни. Заявителями были жите- ли г. Череповец, жившие около металлургического завода. Они жаловались на нарушение их прав в связи с отсутствием защиты от осуществляемого предприятием загрязнения окружающей среды.

В Европейском суде по правам человека заявители утверждали, что в результате загрязнения окружающей среды было нарушено их право на защиту частной жизни и неприкосновенность жилища. Это противоречит предусмотренным Конвенцией гарантиям прав человека. Они считали, что независимо от причин, по которым они проживали в санитарной зоне, выбросы комбината в атмосферу чрезмерны, программа по улучшению экологической обстановки в городе отменена, а информация об экологической ситуации нигде не публикуется. Рассматривая дело, Европейский суд по правам человека сослался на дело «Фадеева против России» и указал, что несмотря на то, что не было установлено, что здоровье Фадеевой было подорвано загрязненной окружающей средой, Суд пришел к выводу, что качество ее частной жизни, безусловно, ухудшилось. В данном деле Суд пришел к аналогичным выводам, указав, что государство-ответчик не предприняло никаких шагов, чтобы реально защитить заявителей от загрязнения окружающей среды: не отселило их в безопасную зону, не предоставило компенсаций, которые бы позволили им переселиться самостоятельно. Кроме того, органы власти в разумное время не реализовали эффективных программ по снижению выбросов. Суд решил, что ст. 8 Конвенции была нарушена, и присудил заявителям компенсацию морального вреда [6].

\section{Дискуссионные вопросы возмещения экологического вреда}

Изучение приведенной выше практики заставляет задуматься над тем, где должна проходить грань между самостоятельной судебной защитой гражданами своих нарушенных экологических прав и публичным (административно-правовым) порядком возмещения экологического вреда здоровью и имуществу граждан, причиненного экологическим правонарушением. Последний предполагает обязанность государства, даже при отсутствии его 
вины, оказывать социальную помощь лицам, которым был причинен экологический вред.

Случаи, когда вред, причиненный жизни и здоровью граждан, принял такие размеры, что его возмещение средствами гражданского права стало невозможным, достаточно хорошо известны в России. Наиболее типичным примером является авария на Чернобыльской АЭС в 1986 году. Как отмечал Конституционный Суд РФ, экстраординарная по своим последствиям авария на Чернобыльской АЭС привела к катастрофическим экологическим и гуманитарным потерям. В результате были существенно нарушены не только право на благоприятную окружающую среду, но и другие конституционные права граждан, связанные с охраной жизни, здоровья, жилища, имущества, а также право на свободное передвижение и выбор места пребывания и жительства, которые ущемлены настолько серьезно, что данный вред оказался невосполнимым. Данная ситуация породила особый характер правоотношений между гражданами и государством, заключающийся в том, что Российская Федерация приняла на себя обязанности по возмещению этого вреда, который, исходя из масштаба и числа пострадавших, не мог быть возмещен в порядке, установленном гражданским, административным, уголовным или иным отраслевым законодательством [7].

Фактически это означает, что Российская Федерация, формально не причастная к аварии на территории соседнего государства (Украины), взяла на себя выплаты всем своим гражданам, пострадавшим от этой катастрофы, поскольку в гражданско-правовом (судебном) порядке их взыскать невозможно. Для этого потребовался специальный публично-правовой механизм выплаты компенсаций, в связи с чем в России, Украине, Беларуси и ряде других республик бывшего СССР (Молдова, Кыргызстан, Таджикистан) были приняты отдельные законы о выплатах компенсаций и предоставлении иных льгот пострадавшим от аварии. Однако вскоре после принятия закона о выплате компенсаций пострадавшим от аварии на Чернобыльской АЭС выяснилось, что государство не выполняет взятых на себя обязательств, в частности, имеет место недостаточное и нерегулярное их финансирование. В течение многих лет про- исходили сбои в программе медицинского обеспечения. Из-за ограниченности средств не всегда удавалось обеспечить медицинские учреждения специальной аппаратурой, реактивами, лекарствами, питанием. До сих пор в очереди на получение жилья стоит несколько тысяч семей инвалидов-ликвидаторов. Невыполнение государством своих обязательств вызвало тысячи судебных исков к органам власти России. Наибольший интерес представляют решения Европейского суда по правам человека, связанные с защитой прав ликвидаторов последствий аварии на Чернобыльской АЭС, среди которых следует упомянуть рассмотренное в 2002 г. ЕСПЧ дело «Бурдов (Burdov) против России» (жалоба № 59498/00).

Наряду с вышеизложенным в рамках доктринального обсуждения проблем возмещения экогенного вреда остается еще, как минимум, две не решенные до конца проблемы:

Во-первых, в зависимости от характера неблагоприятных последствий и формы проявления экологический вред часто подразделяется на реальный и вероятный (предотвращенный). Последнему вопросу посвящена специальная статья 1065 ГК РФ. В рамках этой статьи предъявить иск вправе любое заинтересованное лицо, однако есть ряд неразрешенных проблем, связанных с проблематичностью доказывания причинно-следственных связей между опасным производством и причинением (либо угрозой такого причинения) вреда жизни и здоровью человека, поскольку она не всегда очевидна.

Как справедливо отмечалось в научной литературе, в ст. 1065 ГК РФ речь идет, в том числе, и о правомерной деятельности. Поэтому оспариваемая в рамках этой статьи деятельность, например, химического предприятия может быть правомерной и осуществляться на основании необходимых разрешений и лицензий. Соответственно ее вредные последствия могут и не превышать нормативов ПДК, предусмотренных нормами экологического права. Однако если в результате последних научных разработок будут выявлены новые вредные свойства такого объекта, то это повлечет пересмотр уровня его опасности и заинтересованные лица смогут подать соответствующий иск. Возможность причинения вреда может быть выявлена и в результате об- 
наружения новых свойств объекта, который подвергается вредному воздействию, например, в санитарной зоне завода неожиданно выявляются редкие представители флоры и фауны. Таким образом, даже если деятельность завода является правомерной, это не исключает особых обстоятельств, когда она становится опасной для конкретного лица и начинает создавать угрозу для осуществления его прав [1, с. 146-149].

Во-вторых, требует обсуждения и проблема компенсации морального вреда, причиненного экологическим правонарушением. Под таким вредом в научной литературе понимаются физические и/или нравственные страдания, испытываемые гражданином в результате незаконного посягательства на его экологические и иные, смежные с ними личные неимущественные права и нематериальные блага. Правовая природа морального вреда, причиненного экологическими правонарушениями, определяется публичным интересом, присутствующим в отношениях по его предупреждению и компенсации. Необходимо полноценное использование возможностей коллективных исков (заявленных в защиту нарушенных или оспариваемых прав и законных интересов группы лиц) о компенсации морального вреда, причиненного экологическими правонарушениями. Последнюю надо рассматривать как самостоятельный способ защиты экологических прав человека и меру экологоправовой ответственности [5, с. 8-9].

В настоящий момент в правоприменительной практике России ситуация с компенсацией морального вреда остается недостаточно четко урегулированной. До сих пор нет четких критериев оценки размера компенсации морального вреда за экологические правонарушения, равно как и методов количественной оценки размера компенсации, что порождает на практике большие сложности.

Одним из вариантов частичного смягчения остроты проблемы с возмещением вреда жизни и здоровью граждан, причиненного факторами неблагоприятной окружающей среды, могло бы стать воссоздание системы экологических фондов, существовавших в России в 90-е годы. Тогда действовал внебюджетный (затем консолидированный в бюджет) Экологический фонд (федерального, регионального и местного уровней), в который поступали средства от платы за выбросы, сбросы загрязняющих веществ в окружающую среду, размещение отходов и иные виды загрязнения; сумм, полученных по искам о возмещении вреда, штрафов за экологические правонарушения; средств от реализации конфискованных орудий охоты и рыболовства, незаконно добытой с их помощью продукции. Средства таких экологических фондов могли расходоваться, например, на выплату компенсационных сумм гражданам в порядке возмещения вреда, причиненного их здоровью загрязнением и иными видами негативных воздействий на окружающую среду. Такие выплаты могли производиться и в случаях, когда не удалось установить конкретного причинителя экологического вреда.

К сожалению, с 1 января 2001 г. Федеральный экологический фонд был ликвидирован. Это решение мотивировалось тем, что многочисленные федеральные и региональные целевые фонды показали свою неэффективность, стали источником нецелевого использования средств и коррупции. При этом ряд внебюджетных фондов (Пенсионный фонд, Фонд обязательного медицинского страхования) продолжают существовать до сих пор. В связи с этим мы считаем важным скорейшее возобновление работы Экологического фонда.

\section{Выводы}

Правовые проблемы возмещения вреда, причиненного жизни и здоровью граждан экологическим правонарушением, являются самыми обсуждаемыми вопросами как в теории, так и в правоприменительной практике. Существует ряд недостатков существующих процедур возмещения такого вреда, предусмотренных в гражданском и экологическом законодательстве, связанных с расчетом размера причиненного вреда (в том числе компенсации морального вреда); отсутствием четкого механизма выявления правонарушителей и привлечения их к гражданско-правовой ответственности; недостаточно четко разработан механизм доказывания вины причинителей экологического вреда и т. д. 
Возмещение вреда, причиненного здоровью человека экологическим правонарушением

Одним из вариантов решения этого комплекса проблем могло бы стать воссоздание Экологического фонда или принятие специального Федерального закона «О возмещении вреда, причиненного жизни и здоровью граждан экологическими правонарушениями», который детализировал бы порядок и способы возмещения вреда. Проект такого закона был разработан ровно 20 лет назад [3], однако до сих пор так и не принят, что должно быть исправлено.

\section{СПИСОК ЛИТЕРАТУРЫ}

1. Антонова, Е. А. О предупреждении причинения вреда вследствие деятельности, создающей повышенную опасность для окружающих / Е. А. Антонова // Труды Института государства и права Российской академии наук. - 2010. - № 1. - С. 142-152.

2. Бринчук, М. М. Экологическое право / М. М. Бринчук. - М. : Высшее образование, 2005. $472 \mathrm{c}$.

3. Васильева, М. И. Концепция Федерального закона «О возмещении вреда, причиненного здоровью граждан неблагоприятным воздействием окружающей природной среды» / М. И. Васильева // Зеленый мир. - 1997. - № 9. - С. 6-8.

4. Государственный доклад «О состоянии и об охране окружающей среды Российской Федерации в 2015 г.». - М., 2016. -640 c.

5. Князькин, А. Д. Компенсация морального вреда, причиненного экологическими правонарушениями : автореф. дис. ... канд. юрид. наук / Князькин Андрей Дмитриевич. - М., 2013. - 25 с.

6. Обзор решений Европейского суда по правам человека по российским жалобам за октябрь 2006 г. : (подгот. юристами Центра содействия междунар. защите и Центра «Демос»). - Доступ из справ.-правовой системы «КонсультантПлюс» (дата обращения: 12.03.2017).

7. Постановление Конституционного Суда РФ «По делу о проверке конституционности отдельных положений статьи 1 Федерального закона от 24 ноября 1995 года “О внесении изменений и дополнений в Закон Российской Федерации 'О социальной защите граждан, подвергшихся воздействию радиации вследствие катастрофы на Чернобыльской АЭС"”» от 1 дек. 1997 г. № 18-П. - Доступ из справ.-правовой системы «КонсультантПлюс» (дата обращения: 12.03.2017).

8. Решение Киселевского городского суда Кемеровской области от 31 окт. 2011 г. по делу № 21164/2011 г. - Электрон. текстовые дан. - Режим доступа: https://rospravosudie.com/court-kiselevskij- gorodskoj-sud-kemerovskaya-oblast-s/act-100651102/ (дата обращения: 12.03.2017). - Загл. с экрана.

\section{REFERENCES}

1. Antonova E.A. O preduprezhdenii prichineniya vreda vsledstvie deyatelnosti, sozdayushchey povyshennuyu opasnost dlya okruzhayushchikh [On the Prevention of Harm Infliction due to the Activity Creating the Increased Danger to People around]. Trudy Instituta gosudarstva i prava Rossiyskoy akademii nauk, 2010, no. 1, pp. 142-152.

2. Brinchuk M.M. Ekologicheskoe pravo [Ecological Law]. Moscow, Vysshee obrazovanie Publ., 2005. 472 p.

3. Vasilyeva M.I. Kontseptsiya Federalnogo zakona «O vozmeshchenii vreda, prichinennogo zdorovyu grazhdan neblagopriyatnym vozdeystviem okruzhayushchey prirodnoy sredy») [The Conception of the Federal Law "About Indemnification, Caused to Health of Citizens by Environment's Impact]. Zelenyy mir, 1997, no. 9, pp. 6-8.

4. Gosudarstvennyy doklad «O sostoyanii $i o b$ okhrane okruzhayushchey sredy Rossiyskoy Federatsii v 2015 g.» [The State Report "On the Conditions and Protection of Environment of the Russian Federation in 2015"]. Moscow, 2016. 640 p.

5. Knyazkin A.D. Kompensatsiya moralnogo vreda, prichinennogo ekologicheskimi pravonarusheniyami: avtoref. dis. ... kand. yurid. nauk [Compensation of the Moral Harm Done by Ecological Offenses. Cand. jurid. sci. abs. diss.]. Moscow, 2013. 25 p.

6. Obzor resheniy Evropeyskogo suda po pravam cheloveka po rossiyskim zhalobam za oktyabr 2006 g. : (podgot. yuristami Tsentra sodeystviya mezhdunar. zashchite i Tsentra «Demos») [The Review of Decisions of the European Court of Human Rights on the Russian Complaints for October, 2006: (prepared by lawyers of the Center of assistance to international protection and the Demos Center)]. Access from KonsultantPlyus reference legal system. (accessed March 12, 2017).

7. Postanovlenie Konstitutsionnogo Suda RF «Po delu o proverke konstitutsionnosti otdelnykh polozheniy statyi 1 Federalnogo zakona ot 24 noyabrya 1995 goda "O vnesenii izmeneniy $i$ dopolneniy $v$ Zakon Rossiyskoy Federatsii 'O sotsialnoy zashchite grazhdan, podvergshikhsya vozdeystviyu radiatsii vsledstvie katastrofy na Chernobylskoy AES,”” ot 1 dek. 1997 g. № 18-P [The Decree of the Constitutional Court of the Russian Federation "On the Case of Check of Constitutionality of Separate Provisions of Article 1 of the Federal Law 
of November 24, 1995 "About Modification and Additions in the Law of the Russian Federation 'About Social Protection of the Citizens Who Were Affected by Radiation as a Result of Accident on the Chernobyl Atomic Power Station" of December 1, 1997 no. 18-P]. Access from KonsultantPlyus reference legal system. (accessed March 12, 2017).
8. Reshenie Kiselevskogo gorodskogo suda Kemerovskoy oblasti ot 31 okt. 2011 g. po delu № 2$1164 / 2011 \mathrm{~g}$. [The Decision of the Kiselevsky City Court of the Kemerovo Region of October 31, 2011 on the Case no. 2-1164/2011]. URL: https://rospravosudie. com/court-kiselevskij-gorodskoj-sud-kemerovskayaoblast-s/act-100651102/. (accessed March 12, 2017).

\section{Information about the Authors}

Alexey P. Anisimov, Doctor of Juridical Sciences, Professor, Department of Constitutional and Administrative Law, Volgograd Institute of Management - RANEPA Branch, Gagarina St., 8, 400131 Volgograd, Russian Federation, anisimovap@mail.ru.

Yuliya E. Kayushnikova, Assistant, Department of Constitutional and Administrative Law, Volgograd Institute of Management - RANEPA Branch, Gagarina St., 8, 400131 Volgograd, Russian Federation, Kayshnikova@yandex.ru.

\section{Информация об авторах}

Алексей Павлович Анисимов, доктор юридических наук, профессор кафедры конституционного и административного права, Волгоградский институт управления - филиал РАНХиГС, ул. Гагарина, 8, 400131 г. Волгоград, Российская Федерация, anisimovap@mail.ru.

Юлия Евгеньевна Каюшникова, ассистент кафедры конституционного и административного права, Волгоградский институт управления - филиал РАНХиГС, ул. Гагарина, 8, 400131 г. Волгоград, Российская Федерация, Kayshnikova@yandex.ru. 